\title{
A manutenção do sistema previdenciário afeta a sustentabilidade fiscal do governo? Um estudo de caso do Governo do Estado do Ceará
}

\author{
Does the Maintenance of Social Security System Affect Government Fiscal \\ Sustainability? A Case Study of Government of State of Ceará
}

Paulo Araújo Pontes ${ }^{1}$

\begin{abstract}
Resumo
O tema sustentabilidade fiscal, entendida como a capacidade de um governo manter o orçamento público, intertemporalmente, equilibrado, é um importante condicionante para o desenvolvimento de uma economia. Nesse sentido, deve-se destacar que, nos anos recentes, a sustentabilidade da política fiscal do governo central e dos estados brasileiros têm sido questionada, dado o comportamento do endividamento público e o comportamento das despesas previdenciárias. Assim, este artigo tem como objetivo analisar o impacto que o resultado previdenciário tem na sustentabilidade da política fiscal do Governo do Estado do Ceará. Tendo-se optado por utilizar uma função de reação fiscal, constatou-se que as contas previdenciárias do estado têm influencia negativa na sustentabilidade fiscal do estado e que sua política fiscal é insustentável.
\end{abstract}

Palavras-Chaves: Sustentabilidade Fiscal; Previdência; Ceará.

\begin{abstract}
Fiscal sustainability, understood as the ability of a government to keep the public budget, intertemporally, balanced, is a major constraint for the development of an economy. In this sense, it should be noted that, in recent years, the sustainability of fiscal policy from the Brazilian central government and states have been questioned, given the public debt behavior and the behavior of pension expenses. Thus, this paper aim to analyze the impact that pension income have on the sustainability of the fiscal policy of the Government of Ceará. Having chosen to use a Fiscal Reaction Function, it was found that the state pension accounts have a negative influence on the fiscal sustainability of the state and its fiscal policy is unsustainable.
\end{abstract}

Keywords: Fiscal sustainability; Pension System; Ceará.

\section{Introdução}

A situação fiscal de uma economia é um importante condicionante para o seu desenvolvimento, sendo o descontrole das contas públicas responsável por problemas como a instabilidade de preços, mau desempenho das contas públicas e maiores taxas de juros emlongo prazo, prejudicando as decisões de investimentos dos agentes econômicos (TABOSA ET. AL., 2014).

Nesse sentido, desenvolveu-se considerável literatura sobre a avaliação da sustentabilidade da política fiscal de um governo, podendo-se citar as contribuições de Hamilton e Flavin (1986) e a de Bohn (1998), entre outras, como fundamentais para o estabelecimento de metodologias nessa área do conhecimento.

No Brasil, diversos pesquisadores dedicam-se a análise da questão da sustentabilidade da política fiscal brasileira, podendo-se destacar, entre os trabalhos mais recentes, a contribuição de Luporini (2015) que, para o período 1991 a 2011, conclui que a política fiscal brasileira era sustentável, entretanto a autora fez uma ressalva quanto a política adotada após esse período, sendo necessário análises adicionais para concluir se ela continuava sustentável ou não.

Analista de Políticas Públicas do IPECE e Doutor em Administração Pública pela FGV. Brasil. Afiliação: IPECE. Lattes: http://lattes.cnpq. br/5088287321086620. Orcid: http://orcid.org/0000-0002-9230-1681. Email: paulo.pontes@ipece.ce.gov.br 
Chicoli e Bender (2015), utilizando-se de testes de quebras estruturais, analisaram o período de 2003 a 2014, e concluíram que havia a necessidade de se mudar a política fiscal brasileira, dado que ela não era sustentável. É interessante observar que tanto Luporini (2015) como Chicoli e Bender (2015) analisaram a questão da sustentabilidade da política fiscal brasileira.

Entretanto, como alertam Mora e Giambiagi (2007), o Brasil é uma federação e o comportamento das unidades subnacionais (estados e municípios) têm um relevante papel para a sustentabilidade fiscal. Nesse sentido, Mora e Giambiagi (2007) ressaltam que, de forma recorrente, o desequilíbrio local é transferido para a esfera federal, sendo um exemplo a renegociação das dívidas, no final da década de 1990, que culminou com a promulgação da Lei de Responsabilidade Fiscal (LRF), um exemplo desse caso.

Compreende-se, dessa forma, que a análise da sustentabilidade fiscal não pode restringir-se à política fiscal do governo federal, sendo necessário que ela abarque as políticas fiscais dos entes federativos. Nessa linha, pode-se destacar que Santos (2005), utilizando uma função de reação fiscal e dados em painel, encontrou evidências de que a política fiscal dos estados brasileiros, no período de 1995 a 2004, é sustentável, ou seja, geram maiores superávits primários em resposta ao crescimento da dívida.

Já Caldeira e colaboradores (2016), utilizando-se de uma função de reação fiscal e de métodos de cointegração para o período de 2001 a 2014, conclui que, no conjunto, a política fiscal dos estados brasileiros é sustentável para o período analisado, porém, assim como Luporini (2015), eles alertam para o fato de que o afrouxamento fiscal ocorrido na primeira metade da década de 2010 coloca em dúvida esse resultado.

Em oposição a esse resultado, Tabosa e colaboradores (2014) constataram, para o período 2000 a 2007, que a política fiscal dos estados brasileiros era insustentável. Esses autores utilizaram uma função de reação fiscal para dados em painel e incluíram a possibilidade de não linearidades.

De forma geral, os estudos citados anteriormente analisaram conjuntamente todos os estados brasileiros, sendo estudos dedicados a estados mais incomuns. Entretanto podem-se citar os trabalhos de Cota Junior e colaboradores (2015) e de Locatelli, Ferreira e Patah (2013), que analisaram a sustentabilidade fiscal do estado de Minas Gerais. No primeiro, os autores observam que ocorreu uma melhoria na situação de solvência nas contas públicas mineira logo após a reforma administrativa implantada em 2004. Entretanto houve uma deterioração desse quadro em anos mais recentes. Já Locatelli, Ferreira e Patah (2013), ao analisarem o período de 2002 a 2010, concluíram que o estado de Minas Gerais possui uma política fiscal sustentável.

Um importante fator que influencia na sustentabilidade fiscal dos estados e municípios brasileiros é que eles são obrigados a manterem Regimes Próprios de Previdência Social (RPPS), destinados ao pagamento de aposentadorias e pensões aos seus servidores. Conforme estabelece a Constituição Federal, o RPPS têm caráter contributivo, sendo suas receitas compostas por contribuições dos segurados e do empregador, entretanto, no caso de déficit previdenciário, o setor público é obrigado a financiá-lo com recursos correntes.

Assim, a sustentabilidade do RPPS dos estados tem impacto direto nas contas públicas estaduais, influenciando na sustentabilidade da política fiscal local. Inclusive, é possível identificar diversas análises sobre a sustentabilidade dos regimes previdenciários estaduais e municipais realizado por pesquisadores brasileiros. Nesse sentido, Petrassi (2001), ao analisar a sustentabilidade do RPPS de alguns municípios brasileiros, conclui que eles possuem problemas de longo prazo e que a contratação de novos servidores, a fim de aumentar a base de contribuição, não seria uma solução para esse problema, dado que aumentaria a despesa com pessoal dos municípios.

Já Caetano (2016) conclui que, mesmo com alterações significativas e de alto custo político, não é possível eliminar os déficits dos RPPS estaduais, mas que contribuiriam para minimizar os problemas previdenciários dos estados. Por outro lado, Mesquita e Balbinoto Neto (2013) pontuam que a insuficiência das receitas previdenciárias para o pagamento de aposentadorias ou pensões só seria um problema se o poder público não cobrir os déficits previdenciários, ou seja, se o governo não conseguir realocar outros recursos disponíveis para o sistema previdenciário.

Nesse sentido, torna-se interessante observar as conclusões de Simonasi, Kuory e Matos (2013) que, ao analisarem o RPPS do estado do Ceará, no período de 2003 a 2012, concluíram que ele é insustentável. Nessa análise, os autores utilizaram uma função de reação fiscal adaptada para análise de sistemas 
previdenciários, sendo considerado como insustentável o fato de aumentos da dívida previdenciária estarem associados a uma redução do saldo previdenciário.

Dessa forma, o objetivo deste artigo é analisar o impacto que o resultado previdenciário tem na sustentabilidade da política fiscal de um governo estadual, tendo sido escolhido o Governo do Estado do Ceará para esse fim. Subsidiariamente, analisou-se a sustentabilidade da política fiscal desse ente federativo. Para essa análise, optou-se pelo uso da função de reação fiscal, proposta por Bohn (1998 e 2005), e o emprego de técnicas de multicointegração.

Os resultados encontrados permitem concluir que o pagamento de aposentadorias tem impactado negativamente a capacidade de geração de superávits primários pelo governo cearense, sendo observado que se espera, para os próximos anos, que o déficit previdenciário apresente comportamento ascendente. Esse resultado é particularmente preocupante, pois poderá afetar negativamente a capacidade do estado de prover bens e serviços à população.

\section{Modelo teórico e considerações metodológicas}

Luporini (2015) define que uma política fiscal é sustentável se o governo segue um orçamento, intertemporalmente, equilibrado. Outra definição, dada por Luporini (2006), considera um governo fiscalmente sustentável se ele está ou não acumulando dívidas em excesso que, em uma situação limite, levariam ou ao seu calote ou ao início de um processo inflacionário. Dada as definições acima, e supondo a ausência de ganhos com senhoriagem, a restrição orçamentária do governo é dada por:

$$
D e f_{t}=G_{t}-T_{t}+r_{t} * D_{t-1}
$$

Em que $G_{t}$ é o gasto público primário em $t, T_{t}$ são as receitas primárias em $t, D_{t-1}$ é a dívida pública em t-1, $r_{t}$ representa os juros pagos em t e Def $f_{t}$ e o resultado nominal em $t$. Assim, a dívida em té dada por:

$$
D_{t}=D_{t-1}+D e f_{t}
$$

e o resultado primário em t é dado por:

$$
S_{t}=G_{t}-T_{t}
$$

assim, substituindo-se (3) e (1) em (2) tem-se que:

$$
D_{t}=\left(1+r_{t}\right) * D_{t-1}-S_{t}
$$

Dessa forma, percebe-se que a dívida pública em t é dívida pública de t-1 adicionada dos juros pagos em t e do resultado primário em t. Conclui-se, portanto, que se um governo deseja reduzir sua dívida pública, deverá produzir sucessivos superávits primários que superem pagamento de juros no período t. Uma alternativa a equação (4) é dividir os termos acima por $Y_{t}$, ou seja, considerar as variáveis como proporção do PIB da economia, resultando em:

$$
d_{t}=\frac{\left(1+r_{t}\right)}{\left(1+y_{t}\right)} d_{t-1}-s_{t}
$$

em que $y_{t}$ é a taxa de crescimento do PIB em t. Pela equação (5), constata-se que um maior crescimento da economia no ano t resulta em um menor resultado fiscal para ou manter a dívida pública constante, proporcionalmente ao PIB, ou reduzi-la. Portanto, um maior crescimento econômico pode compensar os efeitos oriundos de uma elevação dos juros.

Dado o arcabouço teórico acima, vários pesquisadores dedicaram-se a análise da sustentabilidade das finanças públicas. Nesse sentido, Costa (2009) elenca duas abordagens metodológicas, entre outras, para se identificar se a política fiscal é sustentável ou não: a primeira forma é o uso da trajetória da relação dívida /PIB e a segunda, os testes de estacionariedade.

A primeira abordagem, a razão dívida/PIB, segundo Luporini (2006), foi apresentada por Evsey Domar e Roy Harrod na década de 1940. A lógica desse tipo de indicador é que o valor da dívida pública, analisado 
de forma isolada, não forneceria muitas informações sobre sua sustentabilidade, assim a divisão pelo PIB seria um indicador mais coerente para esse fim. Nesse sentido, considera-se que as contas públicas são sustentáveis se essa relação estiver constante ou declinando no tempo, e insustentáveis se essa razão estiver aumentando. Os indicadores propostos por Blanchard (1990) são um exemplo desse tipo de indicador.

$\mathrm{Na}$ segunda forma de se analisar a sustentabilidade da política fiscal, os testes de estacionariedade, eles começaram a ser utilizados na década de 1980, após o trabalho seminal de Hamilton e Flavin (1986). Nesse trabalho, os autores consideram que a restrição orçamentária intertemporal é dada por:

$$
D_{t}=A_{0}(1+r)^{t}+E_{t} \sum_{j=1}^{\infty}(1+r)^{-j} S_{t+j}+n_{t}
$$

em que $n_{t}$ é um distúrbio que representa choques na taxa de juros de curto prazo e $A_{0}$ é o valor esperado da dívida pública no futuro, como especificado na fórmula abaixo:

$$
E_{t}\left[\lim _{N \rightarrow \infty} \frac{D_{N}}{(1+r)^{N}}\right]=A_{0} \geq 0
$$

Hamilton e Flavin (1986) consideram que uma política fiscal só é sustentável, se e somente se, $A_{0}=0$. Nesse sentido, eles propõem a realização de testes de estacionaiedade para as séries de resultado fiscal e dívida pública. Se ambas forem não estacionárias, considera-se que a política fiscal é sustentável.

Entretanto Bohn (2005) conclui que a definição de sustentabilidade da política fiscal, em que a dívida pública é igual ao valor presente dos resultados fiscais futuros, é falha. Nesse sentido, Bohn (2005), considerando mercados completos, deriva que a sustentabilidade da política fiscal depende também da condição Não Ponzi, como especificado abaixo:

$$
\lim _{n \rightarrow \infty} E_{t}\left[u_{t, n} * d_{t+n}\right]=0
$$

Complementarmente, Bohn (1998 e 2005) argumenta que os testes de estacionariedade não seriam adequados para identificar se a política fiscal seria ou não sustentável. Como alternativa, Bohn (1998 e 2005) propõe uma metodologia que busca identificar como o governo reage ao aumento da dívida pública. Para tanto, deve-se estimar, por uma regressão, a seguinte equação:

$$
s_{t}=\rho d_{t}+\alpha Z_{t}+\varepsilon_{t}
$$

em que $\varepsilon_{t}$ é um termo de erro com distribuição normal e $Z_{t}$ são outros fatores que influenciam no resultado primário do governo. Essa equação ficou conhecida, posteriormente, como Função de Reação Fiscal. Nesse caso, considera-se que a política fiscal é sustentável se $\rho>0$, isto é, se ocorre um aumento da proporção da dívida pública relativa ao PIB, o governo reage com um incremento do resultado primário.

É interessante observar que Bohn (2005) supõe que, se os políticos preocupam-se com a dívida pública, existe um mecanismo de correção de erro que busca estabilizar a dívida pública ou, ao menos, gera um mecanismo de cointegração entre a dívida e o resultado primário.

Assim, tendo em vista o objetivo deste artigo, optou-se por utilizar a função de reação fiscal, incluindose, entre as variáveis explicativas, o resultado previdenciário do Governo do Estado do Ceará. Dessa forma, a equação a ser estimada é a seguinte:

$$
s_{t}=\rho d_{t}+\alpha_{1} P_{t}+\alpha_{2} \text { Ciclo }_{t}+\varepsilon_{t}
$$

em que $\mathrm{P}_{\mathrm{t}}$ é o resultado previdenciário, Ciclo $\mathrm{t}_{\mathrm{t}}$ é uma variável que busca identificar ciclos econômicos e $\varepsilon_{\mathrm{t}}$ é um termo de erro com distribuição normal. Os coeficientes de maior interesse, neste artigo, serão o $\alpha_{1}$ e $\rho$, em que um coeficiente positivo e significativo para $\alpha_{1}$ é uma evidência de que o resultado previdenciário está contribuindo para uma piora do resultado primário. 
Como ressalta Luporini (2015), o uso da variável Ciclo é justificada pelo fato de que o governo pode optar por incorrer em resultados primários menores em períodos de recessão e por maior controle de gastos em períodos de maior crescimento econômico.

\section{Dados e fontes de dados}

Os dados fiscais aqui utilizados foram obtidos no Desmonstrativo do Resultado Primário e no Demonstrativo das Receitas, no Demonstrativo da Receita Corrente Líquida e Despesas Previdenciárias do Regime Próprio dos Servidores Públicosn constantes no RREO (Relatório Resumido de Execução Orçamentária) do estado do Ceará, disponíveis no site da Secretária da Fazenda. Dessas fontes, foram obtidos os valores do resultado primário do estado, da dívida pública e das despesas primárias. Uma particularidade dessa fonte é que ela possui frequência bimestral e sua divulgação é uma exigência da Lei de Responsabilidade Fiscal.

Dada a frequência bimestral dos dados citados, não é possível calcular a proporção dos dados fiscais com relação ao PIB do estado, dado que esse é calculado apenas de forma anual. Dessa forma, optou-se por utilizar a abordagem de Simonasi, Kuory e Matos (2013), que utilizaram variáveis como proporções da receita corrente líquida.

Já os dados para a variável Ciclo, optou-se pelo uso da série do IBCR-Ce (Índice de Atividade Econômica Regional - Ceará), disponível no site do Banco Central do Brasil. Para a variável Ciclo foi empregado o filtro de Hodrick-Prescott para eliminar os termos de tendência dessas séries, sendo utilizado nas regressões apenas o componente cíclico dessas séries.

Relativamente aos dados fiscais, na Figura 1 são apresentados os comportamentos do resultado primário e previdenciários do estado do Ceará para o período compreendido entre o primeiro bimestre de 2005 e o primeiro bimestre de 2016. Como pode ser observado na referida figura, até o começo do ano de 2011, era comum o governo cearense apresentar significativos superávits primários no início do ano, sendo comum superarem $60 \%$ da RCL.

Entretanto, após o início de 2011, observa-se que a amplitude dos resultados primários diminui e resultados primários deficitários passam a ser mais frequentes a partir desse período. No ano de 2015, essa tendência torna-se mais evidente, tendo havido apenas dois superávits nos dois primeiros bimestres do ano.

Quanto ao resultado previdenciário, ainda na Figura 1, pode-se observar que, até início do ano de 2010, ele apresentou uma certa estabilidade, tendo déficits em torno de $7 \%$ da RCL estadual. Porém, após o ano de 2010, o déficit previdenciário do estado passa a ter um comportamento crescente, tendo sido superior a $20 \%$ em seis períodos ( $3^{\circ}$ e $5^{\circ}$ bimestre de $2011,3^{\circ}$ bimestre de 2012,2013 e 2014 e $4^{\circ}$ bimestre de 2015 ). É interessante observar que há uma coincidência da piora dos déficits previdenciários com a redução dos resultados primários, de modo que pode-se supor que essas duas séries são cointegradas. Na próxima secção será apresentado testes que confirmam essa suposição.

Relativamente à dívida do estado do Ceará, o comportamento dessa série é apresentado na Figura 2 , sendo possível constatar que ela apresentava, até o terceiro bimestre de 2009 , tendência de queda e, a partir de então, há uma reversão desse comportamento, ou seja, passa a aumentar, sendo possível constatar que houve um significativo crescimento entre o quinto bimestre se 2014 e o primeiro bimestre de 2016 .

Dessa forma, dada as informações presentes nas Figuras 1 e 2, é possível observar que os superávits primários do governo estadual eram superiores no período em que a dívida estava em queda e passaram a ser menores no período que a dívida apresentou comportamento crescente. Assim, essa é uma evidência de que a política fiscal do governo do Ceará é insustentável. 
Figura 1 - Resultado primário e resultado previdenciário do estado do Ceará (\% RCL)

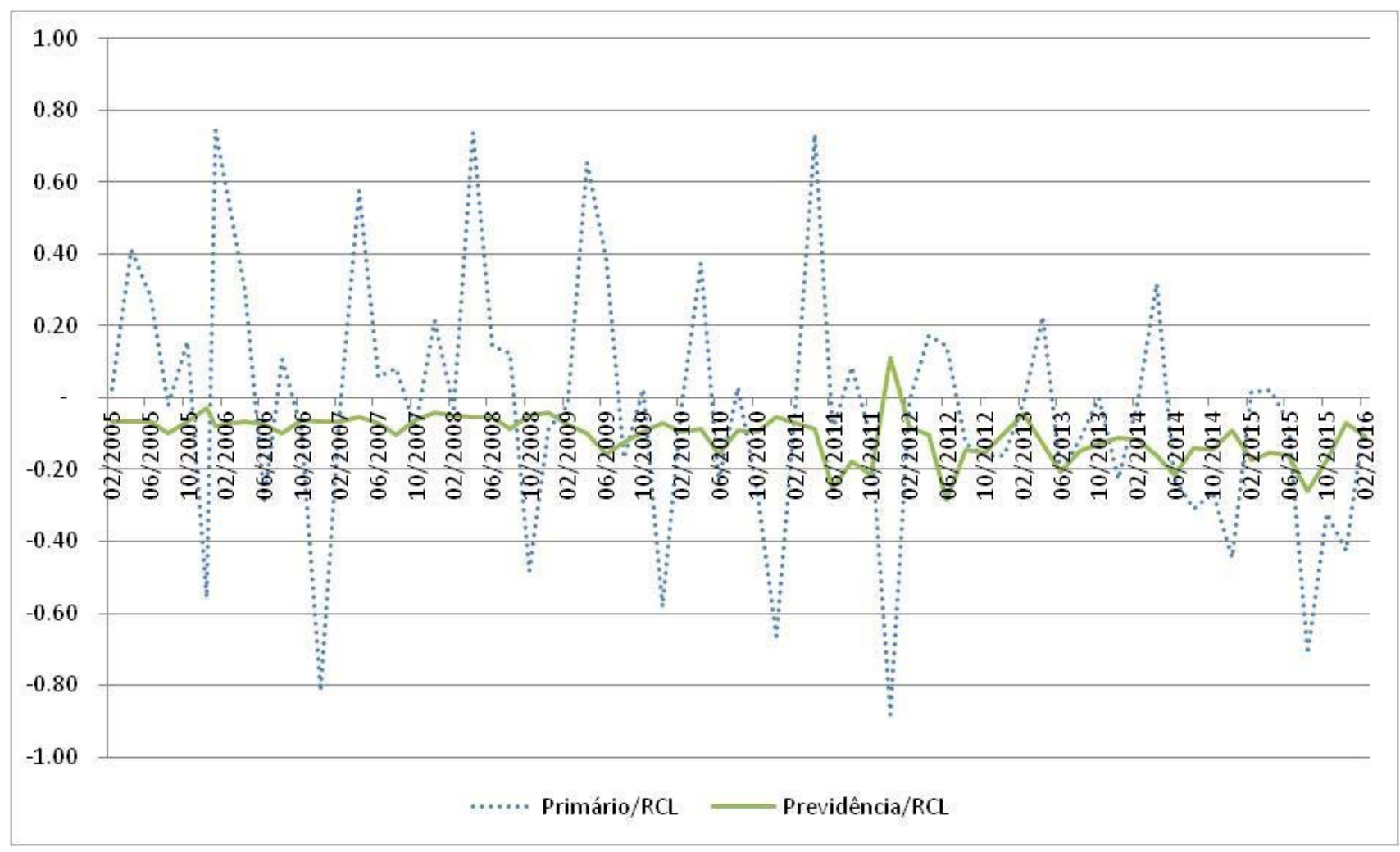

Fonte: Sefaz-Ce

Figura 2 - Dívida corrente líquida do estado do Ceará (\% RCL)

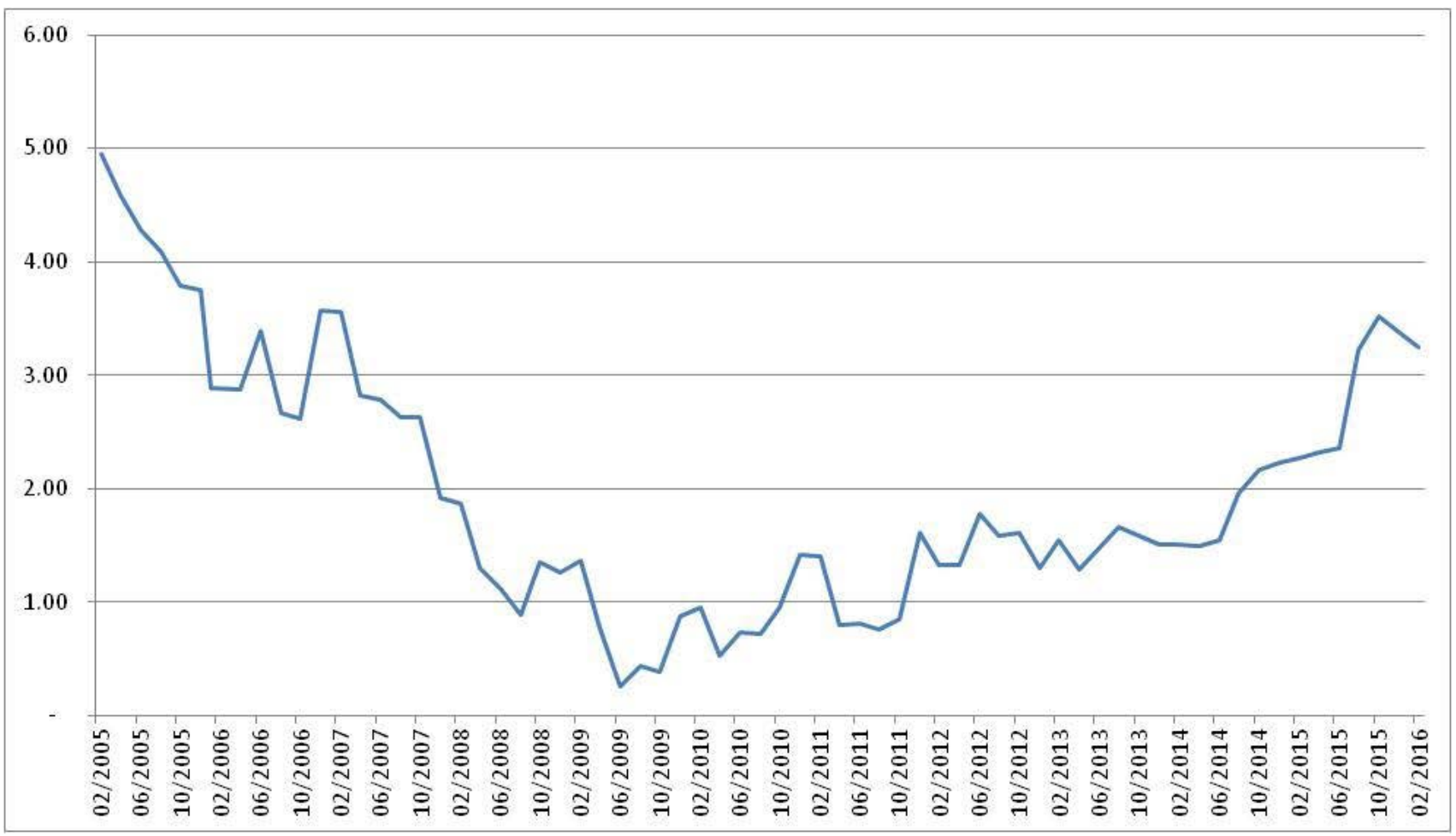

Fonte: Sefaz-Ce 


\section{Resultados}

Diante do exposto, optou-se por estimar a função de reação fiscal por um modelo de correção de erros, sendo esse método de estimação utilizado por Luporini (2016), Chicoli e Bender (2015) e também por Bertussi e Triches (2012). Nesse método, como destacam Enders (2009) e Bueno (2008), supõem-se que existe uma relação de longo prazo entre as variáveis e um mecanismo de correção de erro de curto prazo.

Assim, o primeiro passo é identificar a ordem de integração das séries em análise, sendo os resultados obtidos apresentados na Tabela 1. Como pode ser observado na referida tabela, foram utilizados os testes Augmented Dickey-Fuller (ADF), Dickey-Fuller GLS (ADF-GLS) e KPSS, e foi constatado que as séries em análise são integradas de primeira ordem, permitindo, assim, que se verifique se existe ou não uma relação de longo prazo entre elas.

Tabela 1 - Ordem de integração das séries de resultado primário, DCL e resultado previdenciário.

\begin{tabular}{l|c|c|c}
\hline Variável & ADF & ADF-GLS & KPSS \\
\hline Resultado primário & $\mathrm{I}(1)$ & $\mathrm{I}(1)$ & $\mathrm{I}(1)$ \\
DCL & $\mathrm{I}(1)$ & $\mathrm{I}(1)$ & $\mathrm{I}(1)$ \\
Resultado previdência & $\mathrm{I}(1)$ & $\mathrm{I}(1)$ & $\mathrm{I}(1)$ \\
\hline
\end{tabular}

Fonte: Elaboração própria

Como as séries são integradas de mesma ordem, é possível realizar o teste de cointegração de Johansen, com o qual se pretende identificar se existe uma relação de longo prazo entre as variáveis em análise. Para definição do número de defasagens a serem utilizadas no Teste de Cointegração de Johansen, utilizou-se o critério de informação de Akaiake, Hannan-Quinn e FPE (Erro de Predição Final), que indicam que o VEC deve ser estimado com cinco defasagens.

Como pode ser observado na Tabela 2, o teste de cointegração rejeita a hipótese nula, tanto no teste de traço como no do máximo autovalor, de que não existe cointegração entre as séries e não rejeita a hipótese nula no caso de existir ao menos uma relação de cointegração. Dessa forma, é possível concluir que existe uma relação de longo prazo entre as séries em análise.

Dada a não rejeição da hipótese de que existe ao menos uma relação de cointegração, foi realizada a estimação da função de reação fiscal por um VEC, sendo os resultados obtidos apresentados na Tabela 3. Destaque-se, ainda, que se optou por estimar dois modelos, sendo o primeiro sem variáveis exógenas e o segundo incluindo a variável exógena referente ao ciclo econômico.

Tabela 2 - Testes de cointegração de Johansen para as séries de resultado primário, dívida corrente líquida e resultado previdenciário

\begin{tabular}{l|c|c|c|c}
\hline & Autovalor & Estatística & Valor crítico 5\% & p-valor \\
\hline \multicolumn{5}{l|}{} \\
Teste Traço & 0,542 & 56,708 & 24,275 & 0,000 \\
Aonhum & 0,117 & 8,988 & 12,320 & 0,169 \\
A estatística do traço indica a existência de uma equação de cointegração & \\
\hline
\end{tabular}

Teste máximo autovalor

Nenhum

0,542

47,720

17,797

0,000

Ao menos 1

0,117

7,637

11,224

0,199

O teste do máximo autovalor indica a existência de uma equação de cointegração

\begin{tabular}{lc}
\hline Observações & 61 \\
Número de defasagens & 5
\end{tabular}

Período

Fev/2005 a Fev/2016

Termos determinísticos

Sem Intercepto e Tendência

Fonte: Elaboração própria 
Antes de comentar os resultados expostos na Tabela 3, deve-se atentar para o fato de que "como a dívida líquida e o superávit primário estão contidas em um mesmo vetor, um sinal negativo no vetor de cointegração da razão dívida/PIB representa um sinal positivo no parâmetro dessa variável" (CHICOLI E BENDER, 2015, pg. 11). Portanto, se o sinal do coeficiente $\rho$ for negativo, não se rejeita a hipótese nula de que a política fiscal é sustentável.

Como pode ser constatado na Tabela 3, o coeficiente $\rho$ possui sinal positivo e valor de, aproximadamente, 0,02 , tanto para o modelo com variável exógena como para o que não considera essa variável, e, portanto, aceitasse a hipótese alternativa, ou seja, a política fiscal do governo do Ceará não é sustentável. Deve-se observar que a interpretação do coeficiente é a seguinte: se a dívida líquida do estado aumenta em um ponto percentual, relativo à $\mathrm{RCL}$, o superávit primário é reduzido em 0,02 pontos percentuais da $\mathrm{RCL}$.

Uma ressalva a ser feita sobre a conclusão da não sustentabilidade da política fiscal do estado do Ceará é que ela diz respeito ao fato de não ser aconselhável à manutenção da política fiscal em longo prazo, dado que ela tem aumentado o endividamento público. Assim, observando-se o atual nível da dívida corrente líquida do estado, contata-se que, ao final do $1^{\circ}$ quadrimestre de 2016 , ela estava em $49,77 \%$ da $\mathrm{RCL}$, quando o limite máximo permitido é de $200 \%$. Pode-se supor que o estado está em uma situação solvente. Entretanto, torna-se necessário um constante monitoramento das contas públicas estaduais para evitar que se atinja uma situação de insolvência pela manutenção da política fiscal do estado.

Já o coeficiente da variável resultado previdenciário mostrou-se significativo e negativo. Assim, quanto maior o déficit (superávit) previdenciário, maior será o déficit (superávit) primário registrado. O coeficiente de $\alpha_{1}$ indica que uma piora de um ponto percentual nas contas previdenciárias implica em uma piora de 0,1 ponto percentual do resultado primário.

Esse resultado é particularmente preocupante para as contas públicas estaduais, dado que o déficit do RPPS cearense aumentou significativamente após o ano de 2010. Como pode ser observado na Figura 3, o déficit previdenciário estadual cresceu de $R \$ 565$ milhões, em 2010, para $R \$ 1.010$ milhões, em 2015. Em termos de receita corrente líquida, a despesa saltou de 4,61\%, em 2010, para 7,01\%, em 2015.

Além desse fato, deve-se considerar que, segundo as projeções atuariais constantes no RREO do $6^{\circ}$ bimestre de 2015, o déficit do RPPS do Ceará deverá crescer até o ano de 2024, quando atingirá o valor de $R \$ 3.032$ milhões de reais, isto é, 3 vezes maior do que o observado em 2015.

Tabela 3 - Estimativa da função de reação fiscal

\begin{tabular}{|c|c|c|c|c|c|c|}
\hline \multicolumn{7}{|c|}{ Vetor de cointegração - Relação de longo prazo } \\
\hline$S(-1)$ & \multicolumn{3}{|c|}{1} & \multicolumn{3}{|c|}{1} \\
\hline \multirow{2}{*}{$\mathrm{D}(-1)$} & \multicolumn{3}{|c|}{$0,023585^{*}$} & \multicolumn{3}{|c|}{$0.023543^{*}$} \\
\hline & \multicolumn{3}{|c|}{$[7,58520]$} & \multicolumn{3}{|c|}{$[7.48122]$} \\
\hline \multirow{2}{*}{$P(-1)$} & \multicolumn{3}{|c|}{$-0,100702^{* *}$} & \multicolumn{3}{|c|}{$-0.101387^{\star \star}$} \\
\hline & \multicolumn{3}{|c|}{$[-1,84525]$} & \multicolumn{3}{|c|}{$[-1.83168]$} \\
\hline \multicolumn{7}{|c|}{ Mecanismo de correção de erro - Coeficientes de ajustamento } \\
\hline VEC & $\mathrm{D}(\mathrm{S})$ & $\mathrm{D}(\mathrm{D})$ & $\mathrm{D}(\mathrm{P})$ & $\mathrm{D}(\mathrm{S})$ & $\mathrm{D}(\mathrm{D})$ & $D(P)$ \\
\hline \multirow{2}{*}{$\begin{array}{l}\text { Ajustamento de } \\
\text { curto prazo }\end{array}$} & $-3,087421^{* *}$ & $-0,669577$ & $-0,217646$ & $-3.191449^{* *}$ & -0.53634 & -0.22395 \\
\hline & {$[-1,79843]$} & {$[-0,30682]$} & {$[-0,79752]$} & {$[-1.84753]$} & {$[-0.24422]$} & {$[-0.81042]$} \\
\hline \multirow{2}{*}{$\mathrm{D}(\mathrm{S}(-1))$} & $1,538,639$ & 0,609946 & 0,132818 & 1.629841 & 0.493234 & 0.138365 \\
\hline & {$[1,06779]$} & {$[0,33298]$} & {$[0,57983]$} & [ 1.12380$]$ & [ 0.26751$]$ & [ 0.59639] \\
\hline \multirow{2}{*}{$\mathrm{D}(\mathrm{S}(-2))$} & 0,847703 & 0,453726 & 0,109051 & 0.965809 & 0.302641 & 0.116429 \\
\hline & {$[0,76034]$} & {$[0,32014]$} & {$[0,61530]$} & [ 0.85622$]$ & [ 0.21104] & [ 0.64523$]$ \\
\hline \multirow{2}{*}{$\mathrm{D}(\mathrm{S}(-3))$} & 0,479666 & 0,214396 & $-0,003324$ & 0.574271 & 0.093433 & 0.002638 \\
\hline & {$[0,68096]$} & {$[0,23943]$} & {$[-0,02969]$} & [ 0.80182] & [ 0.10261$]$ & [ 0.02303] \\
\hline \multirow{2}{*}{$\mathrm{D}(\mathrm{S}(-4))$} & $-0,258453$ & 0,569617 & 0,038231 & -0.205203 & 0.501665 & 0.041595 \\
\hline & {$[-0,62702]$} & {$[1,08709]$} & {$[0,58346]$} & {$[-0.49004]$} & [0.94233] & [0.62094] \\
\hline
\end{tabular}




\begin{tabular}{ccccccc}
\hline $\mathrm{D}(\mathrm{S}(-5))$ & $-0,429543^{*}$ & $0,376542^{* *}$ & 0,012936 & $-0.41196^{*} 4$ & $0.354187^{* *}$ & 0.014057 \\
& {$[-2,84929]$} & {$[1,96483]$} & {$[0,53978]$} & {$[-2.69544]$} & {$[1.82283]$} & {$[0.57494]$} \\
$\mathrm{D}(\mathrm{D}(-1))$ & $-0,466266$ & 0,010203 & $-0,03938$ & $-0.48880^{* * *}$ & 0.039156 & -0.0408 \\
& {$[-1,65533]$} & {$[0,02849]$} & {$[-0,87946]$} & {$[-1.72110]$} & {$[0.10845]$} & {$[-0.89790]$} \\
$\mathrm{D}(\mathrm{D}(-2))$ & $-0,551157$ & $-0,225421$ & 0,000871 & -0.544692 & -0.2336 & 0.001355 \\
& {$[-1,65516]$} & {$[-0,53253]$} & {$[0,01645]$} & {$[-1.62910]$} & {$[-0.54956]$} & {$[0.02534]$} \\
$\mathrm{D}(\mathrm{D}(-3))$ & $-0,325939$ & $-0,117186$ & $-0,103923$ & -0.372891 & -0.05699 & -0.10687 \\
& {$[-0,82291]$} & {$[-0,23274]$} & {$[-1,65052]$} & {$[-0.92865]$} & {$[-0.11164]$} & {$[-1.66381]$} \\
$\mathrm{D}(\mathrm{D}(-4))$ & $-0,564705^{* * *}$ & 0,272825 & 0,00364 & $-0.59942^{* * *}$ & 0.317439 & 0.001454 \\
& {$[-1,83411]$} & {$[0,69706]$} & {$[0,07437]$} & {$[-1.92226]$} & {$[0.80072]$} & {$[0.02915]$} \\
$\mathrm{D}(\mathrm{D}(-5))$ & $-0,101673$ & $-0,147411$ & $-0,022727$ & -0.129131 & -0.11218 & -0.02445 \\
& {$[-0,35997]$} & {$[-0,41056]$} & {$[-0,50618]$} & {$[-0.45244]$} & {$[-0.30916]$} & {$[-0.53560]$} \\
$\mathrm{D}(\mathrm{P}(-1))$ & $-0,149752$ & $-1,136,807$ & $-0,909212$ & -0.114174 & -1.18518 & -0.90685 \\
& {$[-0,16861]$} & {$[-1,00686]$} & {$[-6,43958]$} & {$[-0.12784]$} & {$[-1.04381]$} & {$[-6.34726]$} \\
$\mathrm{D}(\mathrm{P}(-2))$ & $-10,555$ & $-0,254439$ & $-0,816807$ & -0.962594 & -0.37526 & -0.81065 \\
& {$[-0,87618]$} & {$[-0,16615]$} & {$[-4,26529]$} & {$[-0.79199]$} & {$[-0.24286]$} & {$[-4.16939]$} \\
$\mathrm{D}(\mathrm{P}(-3))$ & $-0,237923$ & 0,223286 & $-0,930791^{*}$ & -0.163742 & 0.127114 & $-0.92582^{*}$ \\
& {$[-0,20212]$} & {$[0,14922]$} & {$[-4,97425]$} & {$[-0.13809]$} & {$[0.08432]$} & {$[-4.88093]$} \\
$\mathrm{D}(\mathrm{P}(-4))$ & $-0,247004$ & $-0,20565$ & $-0,618215$ & -0.270073 & -0.1774 & -0.6196 \\
& {$[-0,20450]$} & {$[-0,13393]$} & {$[-3,21970]$} & {$[-0.22268]$} & {$[-0.11505]$} & {$[-3.19355]$} \\
$\mathrm{D}(\mathrm{P}(-5))$ & $-0,672456$ & 0,690825 & $-0,503817^{*}$ & -0.741493 & 0.778481 & $-0.50822^{*}$ \\
& {$[-0,67089]$} & {$[0,54217]$} & {$[-3,16193]$} & {$[-0.73442]$} & {$[0.60650]$} & {$[-3.14669]$} \\
\hline IBC-Ce & & & & -0.016474 & 0.021088 & -0.00107 \\
& & & & {$[-0.80689]$} & {$[0.81246]$} & {$[-0.32671]$} \\
\hline $\mathrm{R} 2 \mathrm{Ajustado}$ & 0,606 & 0,02 & 0,605 & 0.603794 & -0.03391 & 0.597052 \\
\hline Estatística $\mathrm{F}$ & 7,171 & 0,898 & 7,12 & 6.714765 & 0.876996 & 6.556408 \\
\hline Observações & 6 & 61 & 61 & 61 & 61 & 61 \\
\hline
\end{tabular}

Fonte: Elaboração própria

${ }^{*}$ Significativo a $1 \%,{ }^{* *}$ Significativo a $5 \%$ e ${ }^{* *}$ significativo a $10 \%$.

Figura 3 - Déficit previdenciário do estado do Ceará (em R \$ de dez/2015 e \%RCL)

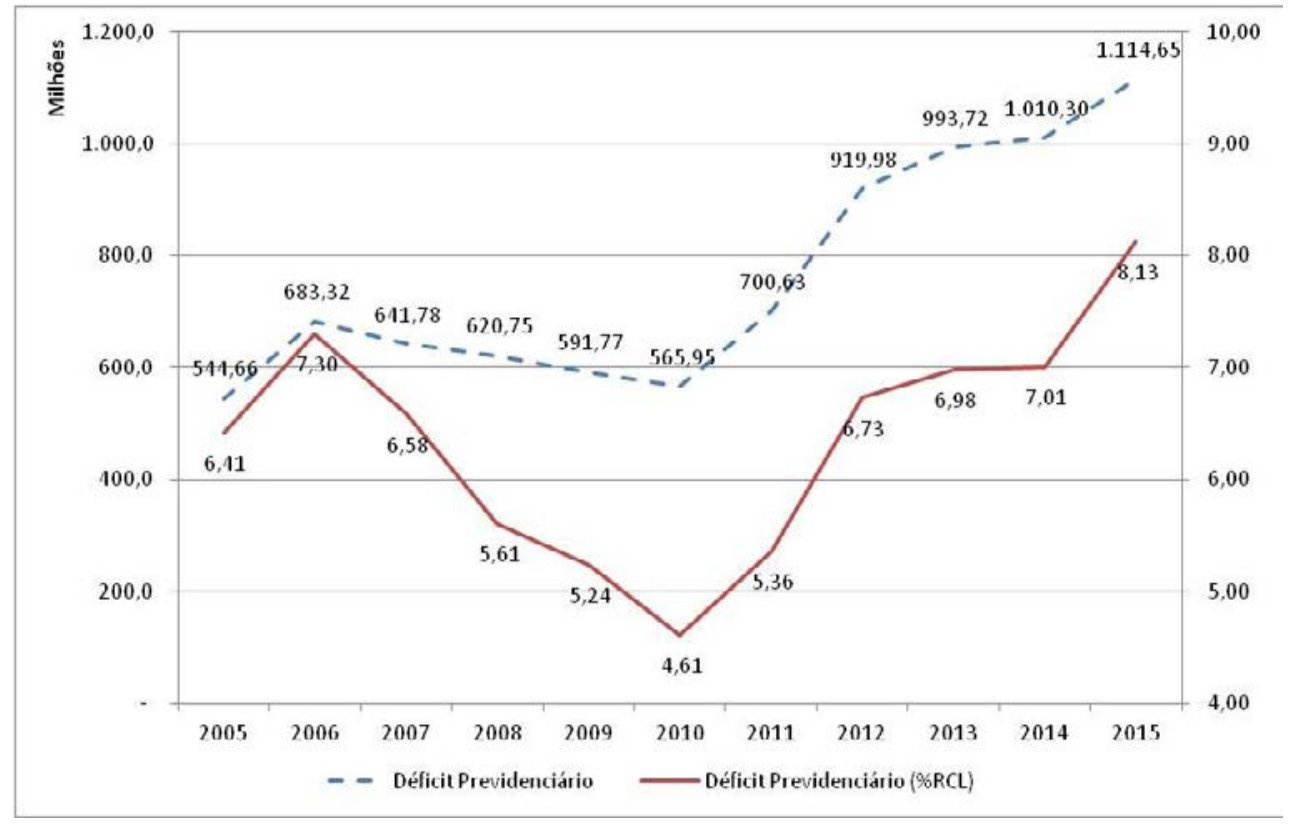

Fonte: Sefaz-Ce 


\section{Notas conclusivas}

A sustentabilidade fiscal tem sido tema de diversas pesquisas, dado que a solvência das contas públicas terão significativos efeitos no desempenho da economia. Nesse sentido, tem-se tanto aprimorado as técnicas de análise quanto muitos pesquisadores têm analisado a política fiscal de diversos países.

No caso brasileiro, a dívida pública do Poder Central e a dos estados têm sido objeto de análise sobre a sustentabilidade ou não da política fiscal nacional ou local. Além disso, tem sido considerado, como abordado anteriormente, que o sistema previdenciário brasileiro é um importante condicionante da situação fiscal da União e dos governos estaduais.

Assim, este ensaio se propôs a analisar a sustentabilidade da política fiscal do do estado do Ceará, e como a manutenção do sistema previdenciário local, o RPPS dos servidores estaduais, afeta a geração de resultados primários. Tendo sido constatado que, em primeiro lugar, a política fiscal do governo cearense não é sustentável em longo prazo, o que irá exigir mudanças em sua condução em algum momento, e que o déficit previdenciário estadual está afetando negativamente a geração de resultados primários.

Com relação ao impacto do resultado previdenciário nas contas públicas estaduais, deve-se destacar que o déficit previdenciário, apresentou, no período de 2010 a 2015, um significativo crescimento, em termos de proporção da RCL estadual, e, pelas informações do RREO do $6^{\circ}$ bimestre de 2015 , deverá crescer de forma ininterrupta até o ano de 2024. Dessa forma, pode-se supor que um cenário em que as contas previdenciárias ocupem parcelas cada vez maiores do orçamento estadual é factível e, se isso ocorrer, é fácil concluir que haverá menos recursos públicos para serem despendidos em outras políticas públicas, ou será necessária a majoração de alíquotas dos impostos arrecadados pelo governo estadual.

Nesse sentido, torna-se necessário buscar mensurar os efeitos que mudanças nas regras de concessão de aposentadorias, como a imposição de uma idade mínima para aposentadoria superior a 60 anos de idade ou a majoração da contribuição previdenciária de ativos e inativos, teriam no comportamento das contas previdenciárias estaduais, buscando-se, ao menos, minimizar os efeitos negativos que o crescimento do déficit previdenciário terá sobre a economia local.

\section{Referencial}

BERTUSSI, Luis Antônio S.; TRICHES, Divanildo. Multicointegração e Políticas Fiscais: Uma Avaliação de Sustentabilidade Fiscal para Argentina, Brasil, México, Peru, Uruguai e Venezuela. Revista Economia, Brasília, v. 13, n. 2, p. 303-325, maio/ago. 2012.

BLANCHARD, Olivier J. Suggestion for a new set of fiscal indicators. Paris: OECD Publishing, 1990. (OECD Economic Department, Working Paper n. 79).

BOHN, Henning. The behavoir of U.S. public debt and deficits. The Quarterly Jornal of Economics, [S.I.], v. 113, n. 3, 1998.

BOHN, $\mathrm{H}$. The sustainability of fiscal policy in the United States. Munich: CESifo Group Munich, 2005. (CESifo Working Paper Series, 1446).

BUENO, Rodrigo de L. da S. Econometria de Séries Temporais. São Paulo: Cengage Learning, 2008.

CAETANO, Marcelo Abi-Ramia. Solvência fiscal de longo prazo dos regimes próprios de previdência dos estados e municípios: texto para discussão 2195. Brasília: IPEA, 2016.

CALDEIRA, Alessandro A.; WILBERT, Marcelo D.; MOREIRA, Tito B. S.; SERRANO, André L. M.

Sustentabilidade da dívida estadual brasileira: uma análise da relação dívida líquida e resultado primário.

Rev. Adm. Pública, Rio de Janeiro, v. 50, n. 2, p. 285-306, mar./abr. 2016.

CHICOLI, Raí da S.; BENDER, Siegfried. Sustentabilidade da dívida pública brasileira: uma análise sobre diversos conceitos de superávit primário e endividamento. In: ENCONTRO NACIONAL DE ECONOMIA DA ANPEC, 43.,2015, Florianópolis. Anais [...]. Florianópolis: ANPEC, 2015.

COTA JUNIOR, Gilmar A.; RODRIGUES, Raphael V. A.; SOUSA, Felipe M. P.; FONSECA, Guilherme 
P. S. Sustentabilidade orçamentária e fiscal dos estados brasileiros: uma análise a partir do estudo de caso do estado de Minas Gerais. In: CONGRESSO CONSAD DE GESTÃO PÚBLICA, 8., 2015, Brasília. Anais [...]. Brasília: CONSAD, 2015.

COSTA, Eugênio Ellery L. Sustentabilidade da Dívida Pública. In: SILVA, Anderson C.; CARVALHO, Lena O. de; MEDEIROS, Otavio L. de (org.). Dívida Pública: a experiência brasileira. Brasília: Secretaria do Tesouro Nacional: Banco Mundial, 2009. p.81-89.

ENDERS, Walter. Applied Econometric Time Series. 30. ed. Alabama: Wiley, 2009.

HAMILTON, James D.; FLAVIN, Marjorie A. On the limitations of government borrowing: a frame work for empirical testing. The American Economic Review, [S.I.], v. 76, n. 4, p. 808-819, 1986.

LOCATELLI, Ronaldo L.; FERREIRA, Valdete G.; PATAH, Leandro A. Análise da Sustentabilidade da Política Fiscal do Estado de Minas Gerais. Revista de Finanças Aplicadas, São Paulo, v.1, p. 1-23, 2013.

LUPORINI, Viviane. Conceitos de Sustentabilidade Fiscal. Niterói, 2006. Texto para Discussão UFF/ Economia, TD 189.

LUPORINI, Viviane. Sustainability of brazilian fiscal policy, once again: corrective policy response over time. Est. Econ., São Paulo, v. 45, n. 2, p. 437-458, abr./jun. 2015.

MESQUITA, Riovaldo A.; BALBINOTO NETO, Giácomo. Produtividade, demografia e sustentabilidade da previdência social. Revista Economia, Brasília, v.14, n.1B, p. 389-427, maio/ago. 2013.

MORA, Mônica; GIAMBIAGI, Fábio. Federalismo e endividamento subnacional: uma discussão sobre sustentabilidade da dívida estadual. Revista de Economia Política, São Paulo, v. 27, n. 3 (107), p. $472-$ 494, jul./set. 2007.

PETRASSI, Myrian Beatriz S. Previdência do servidor público no Brasil: Um Estudo da Sustentabilidade de Regimes Municipais. 2001. Dissertação (Mestrado em Economia)- Pontifícia Universidade Católica, Rio de Janeiro, 2001.

SANTOS, Joanilson de C. Sustentabilidade fiscal dos estados e municípios de capitais no Brasil: uma análise com dados de painel para o período 1995-2004. 2005. Dissertação (Mestrado de Economia)- Universidade de Brasília, Brasília, 2005.

SIMONASSI, Andrei G.; KUORY, Felipe J. F.; MATOS, Paulo Rogério F. Uma função de reação para a análise da sustentabilidade do regime próprio de previdência social dos servidores do estado do Ceará no período 2003-2012. Revista Controle,Fortaleza, v.11, n.2, dez. 2013.

TABOSA, Francisco J. S.; FERREIRA, Roberto T.; KHAN, Ahmad S.; SIMONASSI, Andrei G.; TOMAZ, Daniel. Reação fiscal da dívida pública para os estados brasileiros: uma análise utilizando efeitos limiares. In: ENCONTRO NACIONAL DE ECONOMIA DA ANPEC, 42., 2014, Natal. Anais [...]. Natal: ANPEC, 2014.

Submetido em: 20/04/2017

Aprovado em: 02/05/2019 